\title{
SISTEM INFORMASI MANAJEMEN PAKET EKSPEDISI CV. MK EXPRESS
}

\author{
Izzati Tiara Pratiwi ${ }^{1}$, Zulfikar ${ }^{2}$, Moh. Anshori Aris Widya ${ }^{3}$ \\ 1,2,3 Universitas KH.A.Wahab Hasbullah
}

\section{Article Info:}

Dikirim: 10 Februari 2021

Direvisi: 23 Juni 2021

Diterima: 29 Juni 2021

Tersedia Online: 30 Juni 2021

Penulis Korespondensi: Izzati Tiara Pratiwi

Universitas KH.A.Wahab Hasbullah, Jombang, Indonesia

Email: izzatitiara2@gmail.com

\begin{abstract}
Abstrak: Jasa pengiriman barang atau ekspedisi merupakan salah satu jenis usaha yang banyak dibutuhkan saat ini. Hal ini didukung dengan banyaknya permintaan pelanggan terhadap layanan pengiriman barang. CV. MK Express adalah perusahaan baru dibidang jasa ekspedisi barang, sehingga memerlukan suatu inovasi layanan agar dapat bersaing dengan perusahaan kompetitor yang sudah ada. Inovasi tersebut ialah sistem informasi manajemen pengiriman paket. Sistem tersebut memiliki fitur antara lain pelacakan paket secara realtime, penjemputan paket, pengiriman paket dan laporan transaksi. Dengan suatu sistem informasi manejemen perusahaan akan lebih mudah dalam proses pengarsipan, pelaporan dan pelayanannya kepada pelanggan. Sistem ini dibuat menggunakan database MySQL Server dan menggunakan framework Codeigniter. Sistem terdiri dari front end dan back end. Back end mempunyai fungsi utama memanejemen proses transaksi dan pelaporan. Sedangkan front end digunakan untuk pelanggan melakukan pelacakan paket dan pengecekan ongkos kirim.
\end{abstract}

Kata kunci: ekspedisi; inovasi; sistem informasi manajemen.

\begin{abstract}
Freight forwarding or expedition is one type of business that is much needed today. This is supported by the large number of consumer requests for goods delivery services. $C V$. MK Express is a new company in the field of freight forwarding services, so it requires a service innovation in order to compete with existing competing companies. This innovation is realized with a package delivery management information system. The system has features including real-time package tracking, package pick-up, package delivery and transaction reports. With a company management information system will be easier in the process of filing, reporting and services to customers. The method in the development above uses the waterfall method which is commonly used. The resulting system can facilitate the company in reporting, tracking and processing transactions.
\end{abstract}

Keywords: expedition; innovation; management information systems. 


\section{PENDAHULUAN}

Pengiriman barang adalah salah satu cabang dari berbagai perusahaan yang bergerak dalam bidang jasa[1].Jasa Ekspedisi Angkutan Barang merupakan jasa yang berhubungan dengan penerimaan, angkutan, pengkonsolidasian, penyimpanan, penyerahan, logistik dan distribusi barang beserta jasa tambahan dan jasa pemberian nasehat[2]. Kebutuhan masyarakat yang tinggi akan jasa pengiriman barang, menjadi sebuah peluang bisnis tersendiri bagi para pelaku bisnis ekspedisi[3]. Bisnis ini mulai dilirik banyak pelaku usaha disebabkan oleh semakin banyaknya pengiriman barang dalam transaksi online .Persaingan antara perusahaan-perusahaan ekspedisi semakin sengit dimana pelanggan akan lebih mengutamakan untuk memilih perusahaan yang menyediakan akses informasi yang tersedia dengan cepat[4].Serta adanya suatu sistem informasi pada masa sekarang sudah menjadi kebutuhan bagi perusahaan[5].Sistem Informasi berguna sebagai acuan untuk pengambilan keputusan dalam sebuah organisasi atau perusahaan [6].

CV. MK Express adalah perusahaan baru di bidang jasa ekspedisi barang, Pada ekspedisi barang ini membutuhkan teknologi informasi yang dapat membantu dalam mengelola dan menyimpan data yang akan digunakan untuk membantu proses manajerial yang didapatkan melalui Sistem Informasi Manajemen [7]. Dan membutuhkan suatu inovasi layanan agar dapat bersaing dengan perusahaan kompetitor yang sudah ada. Inovasi tersebut ialah sistem informasi manajemen paket. Sistem tersebut memiliki fitur antara lain pelacakan paket, penjemputan paket, pengiriman paket, dan laporan transaksi.Sistem yang akan dibangun ini berbasis web terdiri dari sisi front end dan back end.Sistem dibuat dengan menggunakan database MySql dan Framwork Codeigniter dengan bahasa pemrograman php dan java script. MySQL merupakan salah satu jenis database server yang amat terkenal. Hal tersebut karena Mysql menggunakan SQL sebagai bahasa dasar untuk mengakses databasenya. Mysql termasuk jenis RDBMS (Relational Database Management System)[8].Sedangkan CodeIgniter adalah kerangka kerja PHP yang kuat dengan ukuran yang sangat kecil, dibuat untuk pengembang yang membutuhkan perangkat sederhana dan elegan untuk membuat aplikasi web berfitur lengkap[9].Codeigniter merupakan suatu Web Application Framework (WAF) yang dirancang khusus untuk mempermudah para developer web dalam mengembangkan apilkasi berbasis web[10].

\section{METODOLOGI PENELITIAN}

Penelitian ini dilakukan melalui beberapa tahapan. Adapun metode yang digunakan dalam tiap-tiap tahapan dapat dilihat dari gambar 1 berikut:

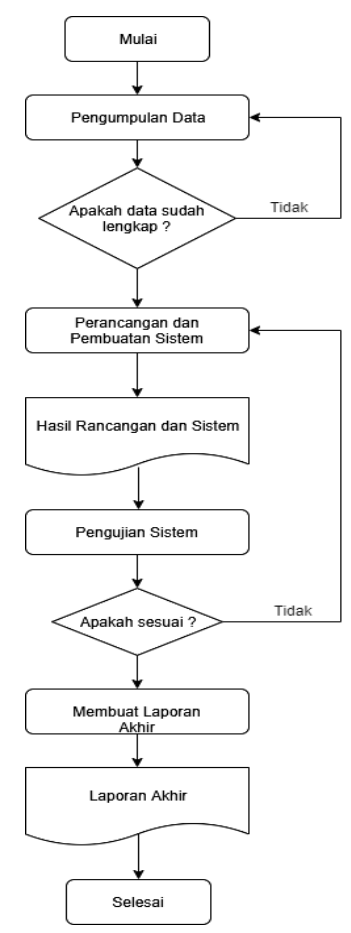

\section{Gambar 1. Flowchart Alur Penelitian}

\subsection{Metode Pengumpulan Data}

Pengumpulan data yang dilakukan melalui beberapa cara yaitu : studi pustaka, wawancara, dan observasi lapangan atau pengamatan secara langsung.

1) Studi Pustaka

Metode ini dilakukan dengan cara mengumpulkan beberapa data terkait bahasan pada penelitian, datadata tersebut diambil dari sumber-sumber relevan seperti buku, jurnal nasional dan internasional. 
2) Wawancara

Wawancara dilakukan dengan pihak yang terkait yaitu pemilik CV MK Express. Dilakukan dengan cara memberikan beberapa pertanyaan untuk dapat mengetahui masalah yang dihadapi sehingga lebih mudah untuk mencari solusi terhadap masalah tersebut.

3) Observasi Lapangan

Pada tahapan observasi peneliti melakukan beberapa observasi pada tempat dan sumber yang menjadi fokus penelitian.

\subsection{Metode Rekayasa Perangkat Lunak}

Perangkat lunak dalam penelitian ini dibangun dengan menggunakan metode Prototype dengan tahapan sebagai berikut:

1) Analisa Kebutuhan

Analisa kebutuhan dilakukan dengan menggali informasi apa saja yang dibutuhkan pihak CV MK Express agar sistem yang dibuat nantinya sesuai dengan yang dibutuhkan.

2) Desain Sistem

Desain sistem yang dirancang pada penelitian ini adalah dengan membuat Desain Flowchart Admin, Flowchart Operator dan Database Design.

3) Membangun Prototype

Pembangunan Prototype sistem menggunakan metode pengembangan Prototyping, bahasa pemrograman PHP dan database nya MySQL.

4) Evaluasi dan Perbaikan

Setelah melakukan implementasi dilakukan tahapan testing menggunakan metode Black Box.

\section{HASIL DAN PEMBAHASAN}

\subsection{Analisis Sistem yang Berjalan}

Pelayanan jasa ekspedisi yang dilakukan oleh CV MK Express saat ini sesuai dengan Standar Operasional Prosedur yang telah ada. Pada gambar 2 Dijelaskan bawa pelanggan yang ingin mengirimkan barangnya harus datang ke kantor CV MK Express, bagian operator mencatat secara manual identitas paket yang akan dikirimkan oleh pelanggan, setelah didata oleh operator kemudian dilakukan pencetakan resi dan label pengiriman barang, resi diberikan kepada pelanggan sedangkan label pengiriman ditempel ke barang. Selanjutnya barang akan dikirimkan sesuai antrian. Proses pengecekan status layanan dan lokasi barang harus dilakukan dengan cara menelfon kurir atau ditanyakan langsung ke kantor CV MK Express. Akses pemberian informasi layanan atau bagi pelanggan dilakukan secara langsung oleh karyawan ke pelanggan.

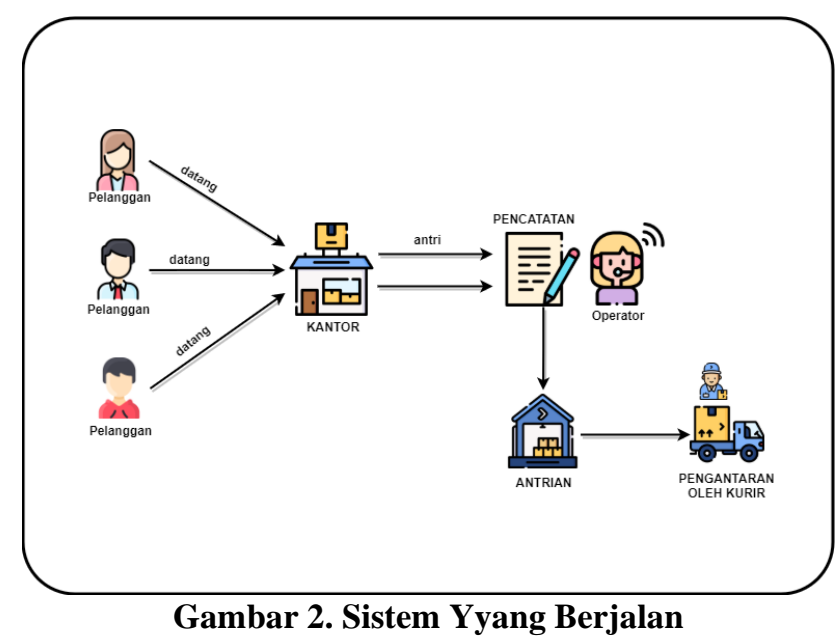

Secara pelayanan CV MK Express sudah terlihat prosedural, namun hal ini dianggap memiliki beberapa kelemahan, antara lain :

1) Belum adanya data digital

Pelayanan ekspedisi di CV MK Express masih menggunakan sistem konvensional, sehingga belum mempunyai data digital seperti database pelanggan, database harga dan database pengiriman. Hal ini juga mengakibatkan sering terjadinya human eror saat melakukan transaksi.

2) Sistem Pengarsipan dan Pelaporan

Setelah melakukan transaksi, pengarsipan masih terbatas pada bentuk fisik saja, sehingga membutuhkan waktu yang relatif lebih lama untuk mencari bukti transaksi dan membuat pelaporan. 
3) Pelacakan paket

Pelacakan paket oleh pelanggan sangat terbatas karena untuk mengetahui barangnya sudah sampai ke tujuan saja, pelanggan harus bertanya langsung baik dengan datang ke kantor maupun melalui via telepon atau chat dan juga menghubungi pihak yang dituju.

4) Layanan pick up (jemput) barang Belum tersedianya layanan pick up (jemput) barang mengakibatkan menumpuknya antrian di kantor CV MK Express.

5) Pengecekan ongkos kirim

Pelanggan harus datang ke kantor aatau kurir untuk mengecek harga pengiriman paket.

6) Layanan Pemberian informasi

Akses informasi bagi publik lebih terbatas karena dilakukan secara langsung sehingga jangkauan informasi kurang luas.

\subsection{Analisis Sistem yang Diusulkan}

Berdasarkan pada analisis sistem yang berjalan, untuk mengatasi masalah-masalah yang ada pada basis data, sistem pengarsipan dan pelaporan, pelacakan paket dan layanan pickup (jemput barang), maka diusulkan sebuah sistem berbasis Web yang didukung sistem mobile oleh pihak ketiga.

Dengan dibuatnya sistem ini diharapkan dapat membantu dalam memanajeman sistem perusahaan baik dalam pelaporan, pengarsipan, pelacakan paket dan layanan pick up (jemput barang). Sistem Transaksi dan pelaporan akan lebih terorganisir, penyebaran informasi bagi publik menjadi lebih luas, sedangkan untuk pelacakan dapat memanfaatkan pengecekan lokasi paket dan ongkos kirim dapat dilakukan dengan front end tanpa harus bertanya ke kantor. Untuk lebih jelasnya mengenai sistem yang diusulkan dapat dilihat pada gambar 3, gambar 4 dan gambar 5 berikut:

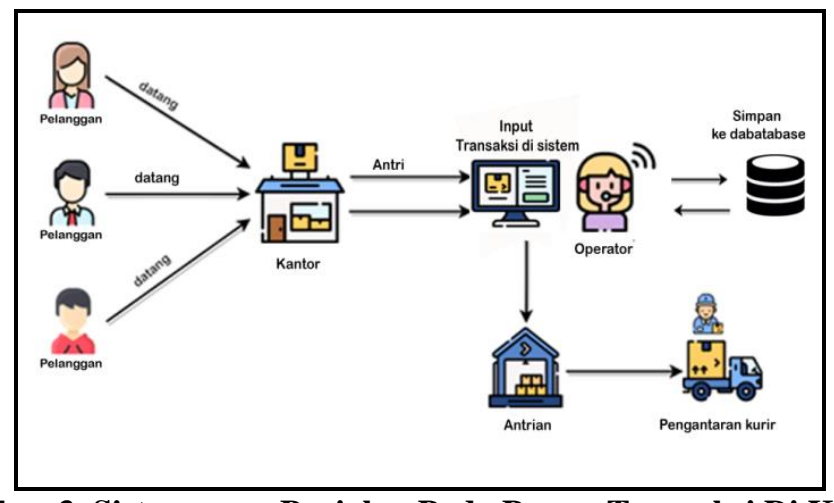

\section{Gambar 3. Sistem yang Berjalan Pada Proses Transaksi Di Kantor}

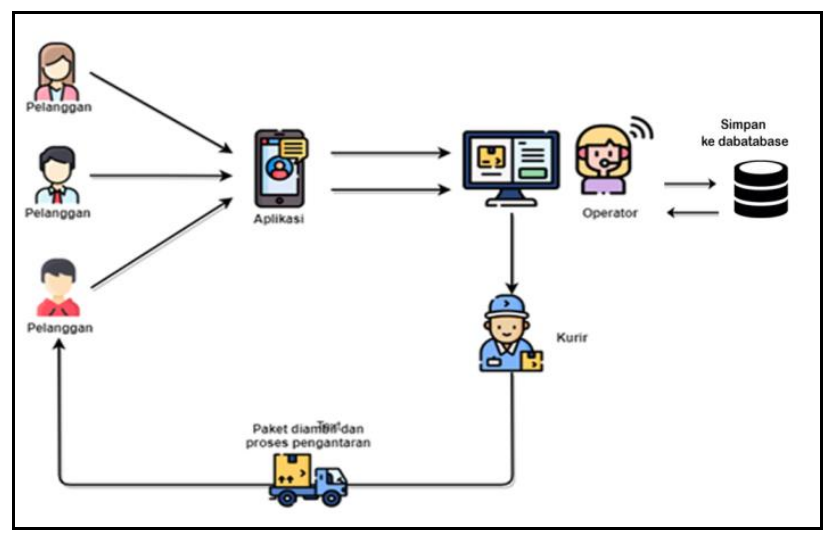

Gambar 4. Sistem yang Berjalan Pada Proses Pick Up 


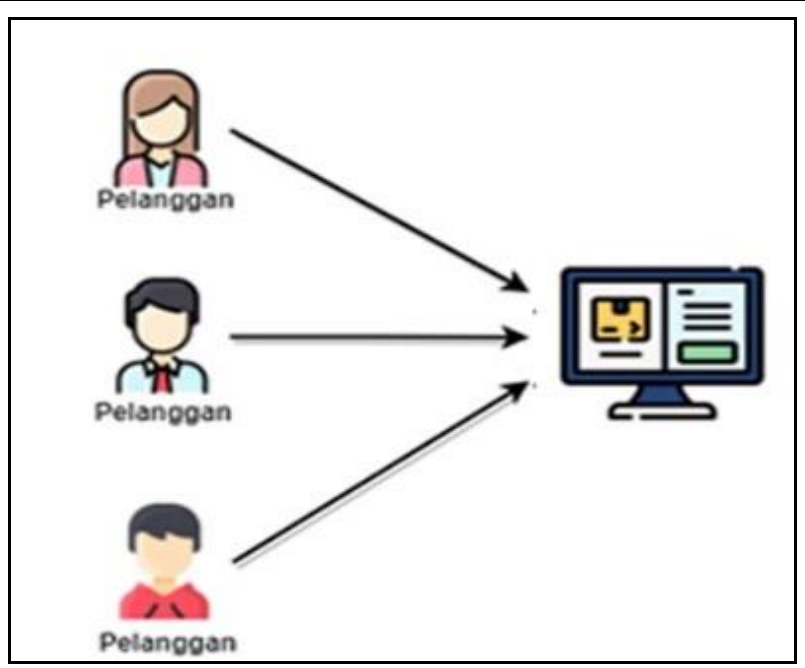

Gambar 5. Pelanggan Mengakses Informasi Di Web

\subsection{Kebutuhan Fungsional}

Kebutuhan fungsional merupakan kebutuhan yang berisi proses-proses yang nantinya dapat dilakukan oleh system. Sedangkan untuk kebutuhan input, proses, output secara berurutan dapat dilihat pada Tabel 1, Tabel 2, dan Tabel 3.

Tabel 1. Kebutuhan input

\begin{tabular}{cll}
\hline No & Jenis & Keterangan \\
\hline 1. & Data Admin & Digunakan untuk perancangan tabel Admin \\
2. & Data Pelanggan & Digunakan untuk perancangan tabel pelanggan dan transaksi \\
3. & Data Karyawan & Digunakan untuk perancangan tabel kurir,operator,staff \\
4. & Data Jenis Barang & Digunakan untuk perancangan tabel barang \\
5. & Data Pengiriman & Digunakan untuk perancangan tabel wilayah \\
6. & Data Wilayah & Digunakan untuk perancangan tabel desa, kecamatan, \\
& & kabupaten dan provinsi \\
7. & Data Harga & Digunakan untuk perancangan tabel harga \\
8. & Data Member & Digunakan untuk perancangan tabel pelanggan \\
\hline
\end{tabular}

\section{Tabel 2. Kebutuhan Proses}

\begin{tabular}{lll}
\hline No. & Jenis & Keterangan \\
\hline 1. & Pendaftaran Pelanggan & Digunakan untuk mendaftar sebagai Pelanggan \\
2. & Tambah Transaksi & Digunakan untuk proses permintaan transaksi baru \\
3. & Cetak laporan transaksi & Digunakan untuk mencetak laporan transasksi \\
4. & Lacak paket & Digunakan untuk melacak lokasi paket \\
5. & Permintaan cek harga & Digunakan untuk mengecek harga \\
\hline
\end{tabular}

Tabel 3. Kebutuhan Output

\begin{tabular}{lll}
\hline No. & Jenis & Keterangan \\
\hline 1. & Label Pengiriman & Output dari proses transaksi \\
2. & Riwayat Pengiriman & Output dari proses transaksi \\
3. & Tracking & Output dari lacak paket \\
4. & Laporan transaksi & Output dari proses transaksi \\
5. & Laporan Lainnya & Bentuk Laporan dengan keperluan tertentu \\
\hline
\end{tabular}




\subsection{Perancangan Sistem}

\subsubsection{Diagram Level Konteks Sistem}

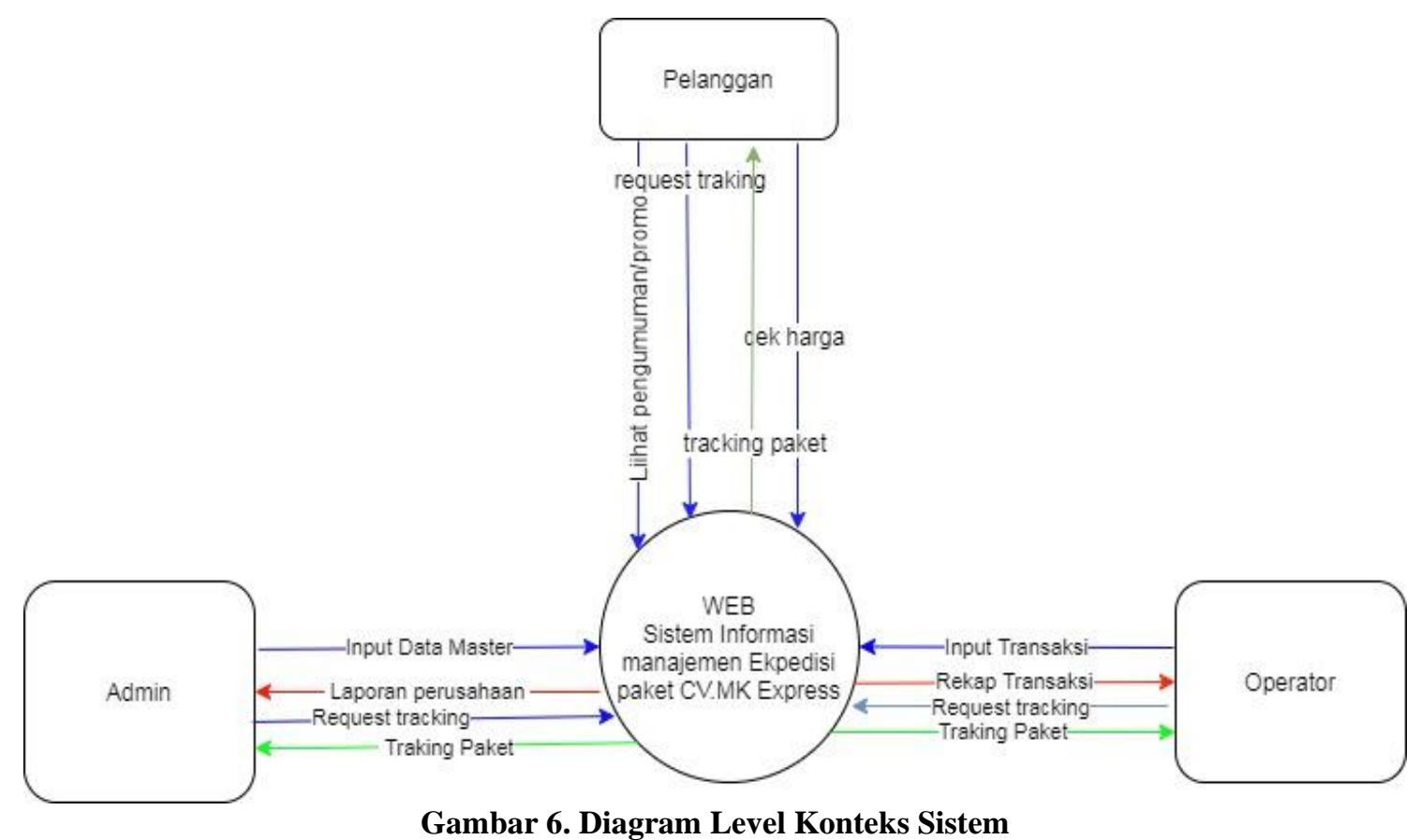

Dari diagram pada gambar 6 diatas dapat dilihat bahwa pada system ini terdapat admin ,operator dan pelanggan Admin bertindak ssebagai master yang bisa melakukan CRUD data master. Sedangkan tugas utama operator adalah melakukan proses transaksi dan pembuatan laporan. Untuk pelanggan memiliki fitur pengecekan ongkos kirim, lacak paket dan info pengumuman atau promo dari MK Express.

\subsubsection{Flowchart Sistem}

Flowchart pada sistem ini berfungsi sebagai alur sistem dan mempermudah untuk pengerjaan serta memahami alur sistem yang akan dikerjakan.

a. Flowchart Admin

Flowchart ini adalah flowchart tentang alur level Admin, dapat dilihat pada Gambar 7 bahwa Admin merupakan master dan bisa melakukan penginputan data master (pelanggan, wilayah, harga, jenis barang, karyawan, member), data transaksi dan laporan untuk menjelaskan apasaja yang bisa dilakukan pada system ini. Serta menjelaskan tentang proses input yang dapat dilakukan oleh admin 


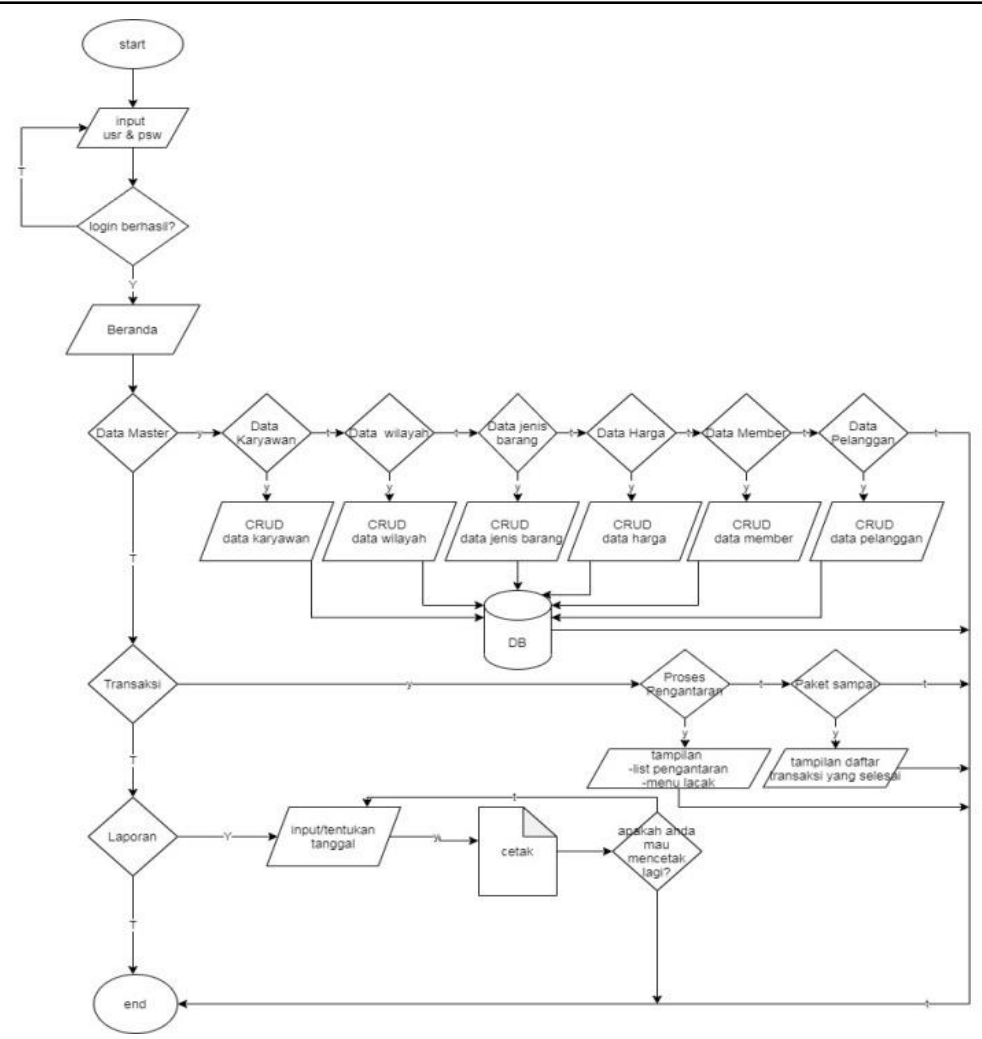

Gambar 7. Flowchart Admin

b. Flowchart Operator

Flowchart pada Gambar 8 dibawah adalah flowchart alur Level Operator. Pada sistem ini Operator dapat hanya dapat mengakses yang tersedia di beranda menu dan sub menu di transaksi dan laporan.

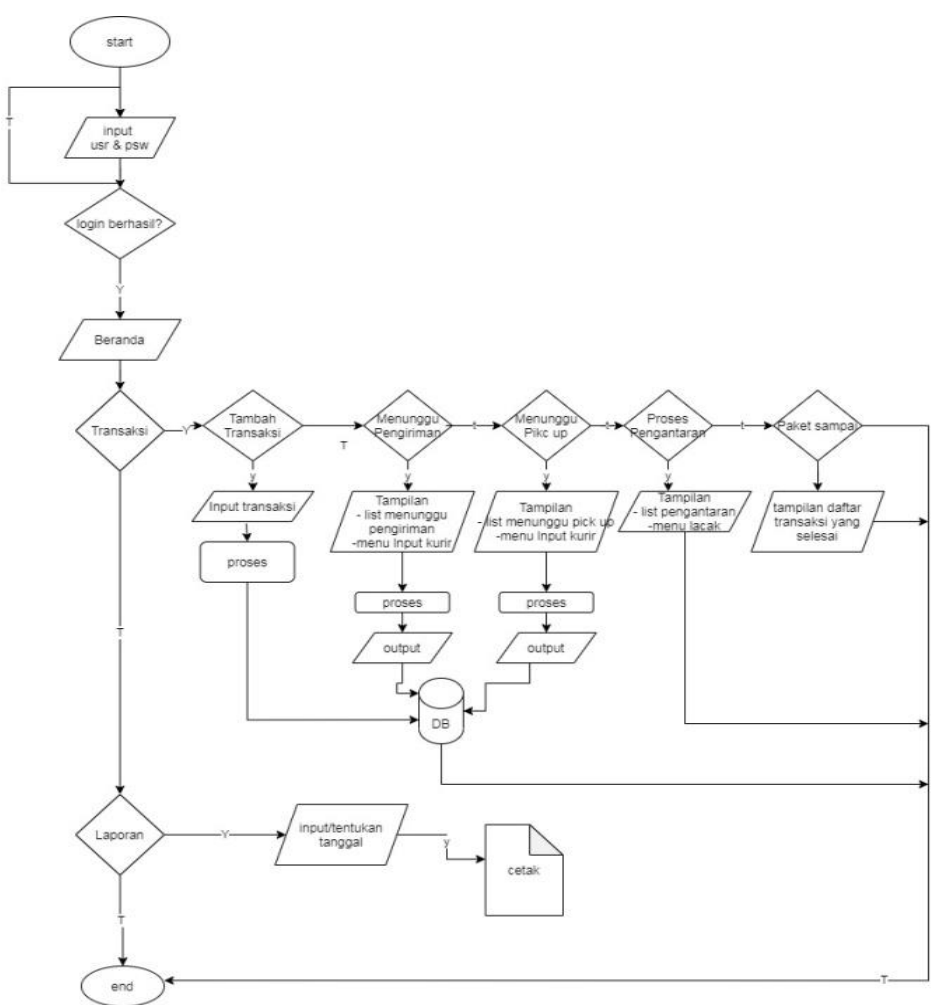

Gambar 8. Flowchart Operator

c. Flowchart Pelanggan

Flowchart gambar 9 dibawah adalah flowchart alur level Pelanggan. Pada sistem ini pelanggan dapat hanya dapat mengakses front end untuk penecekan harga, lacak paket dan info lainnya. 


\subsubsection{Class Diagram}

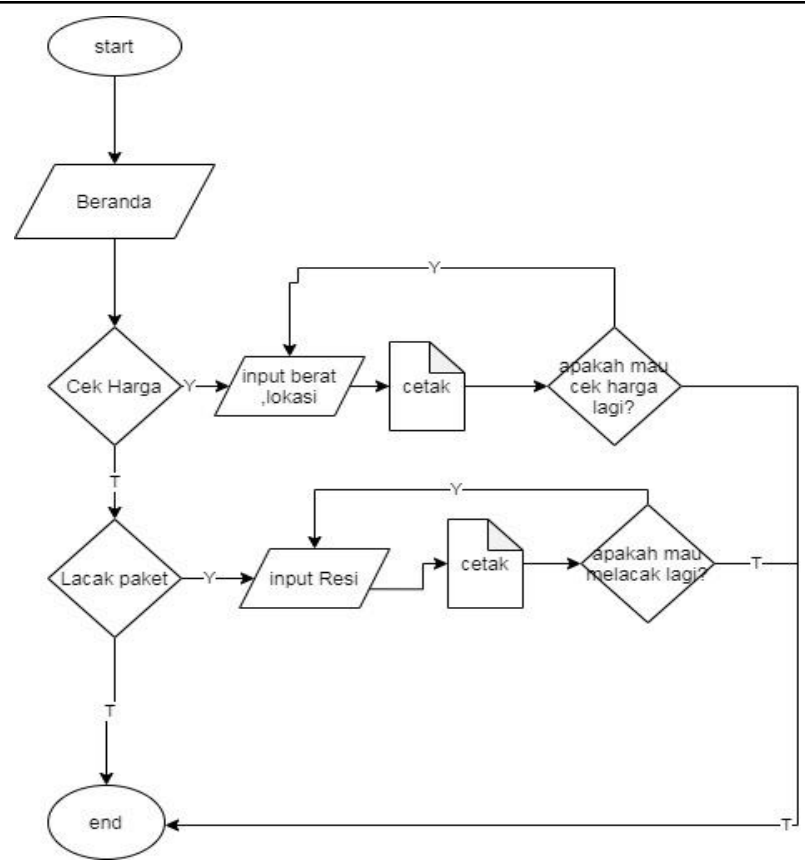

Gambar 9. Flowchart Pelanggan

Class diagram digunakan untuk pemodelan pada basis data. Pemodelannya dapat dilihat pada Gambar 10 yakni terdiri dari kelas-kelas yang saling berelasi serta terdiri dari atribut dan method.

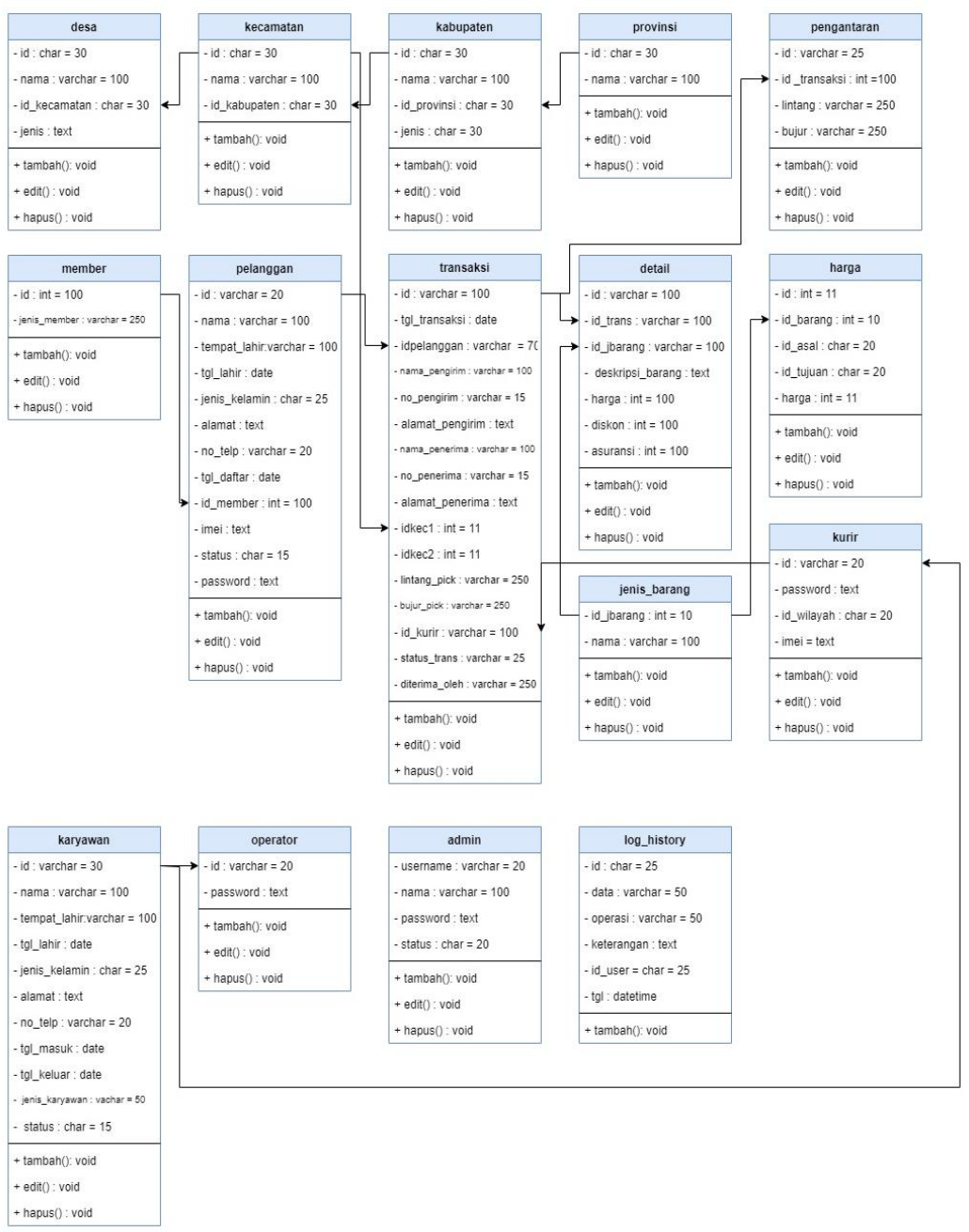

Gambar 10. Class Diagram 


\subsubsection{Rancangan User Interface}

Antarmuka pemakai (user interface) adalah aspek sistem komputer atau program yang dapat dilihat, didengar, atau dipersiapkan oleh pengguna, untuk mengendalikan operasi dan memasukkan data. Pada gambar 11 berikut ini merupakan contoh perancangan antarmuka Sistem Informasi Manajemen Paket Ekspedisi CV MK Express pada menu transaksi.

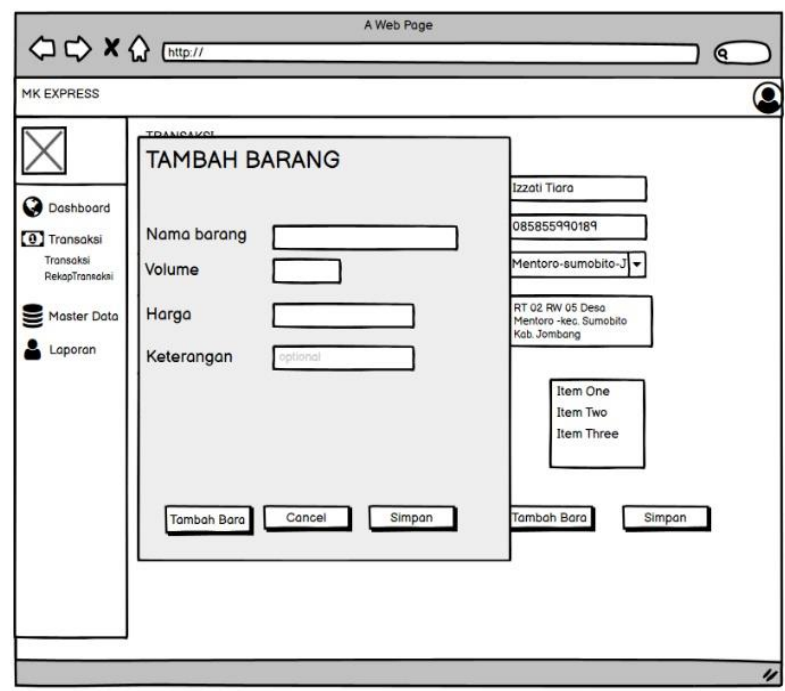

Gambar 11. Perancangan Antar Muka Halaman Transaksi

\subsection{Pembahasan}

Tahapan ini dilakukan setelah perancangan telah selesai, selanjutnya diimplementasikan pada bahasa pemrograman. Kemudian pengujian dilakukan terhadap sistem, untuk memudahkan dalam pengembangan selanjutnya.

\subsection{Implementasi Sistem}

Setelah sistem secara terperinci dianalisis dan didesain maka langkah berikutnya adalah melakukan tahapan implementasi. Tahapan ini bertujuan untuk meletakkan sistem sehingga siap untuk dioperasionalkan, dengan begitu pengguna dapat memberikan masukan atau saran untuk pengembangan sistem di masa depan.Sistem ini dibangun menggunakan bahasa pemograman PHP, Database-nya menggunakan MySQL,Tools yang digunakan Antara lain: sublime, xampp, google chrome.

a. Implementasi Basis Data

Implementasi basis data dapat diambil berdasarkan perancangan basis data yang telah dibuat sebelumnya. Secara fisik implementasi dilakukan menggunakan perangkat lunak MySQL dengan script DDL (Data Definition Language). Pada gambar 12 berikut ini merupakan salah satu contoh implementasi database dalam pembuatan tabel pelanggan. 


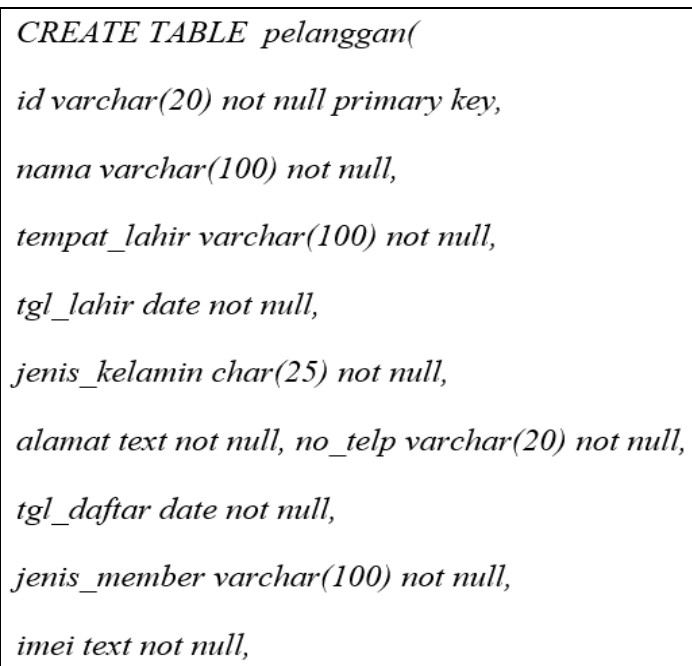

Gambar 12. Pembuatan Tabel Pelanggan

b. Pengkodeaan Program

Pada bagian ini kode program yang ditampilkan yaitu pada pengkodean untuk Operator di controler Operator.php. Potongan kode program Operator.php ini dapat dilihat pada gambar 13.

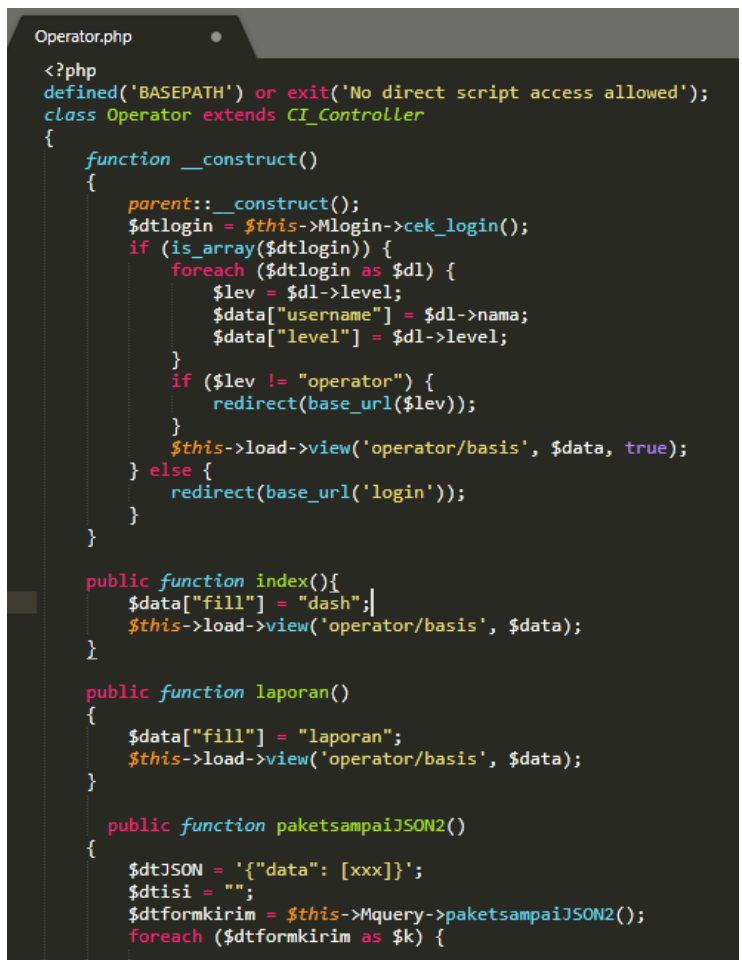

Gambar 13. Kode Controler.php

c. Implementasi Interface

Implementasi interface dilakukan pada setiap form yang telah dibuat dalam aplikasi. Pada gambar 14, gambar 15 dan gambar 16 di bawah ini adalah beberapa tampilan interface pada sistem yang sudah dibuat diataranya :

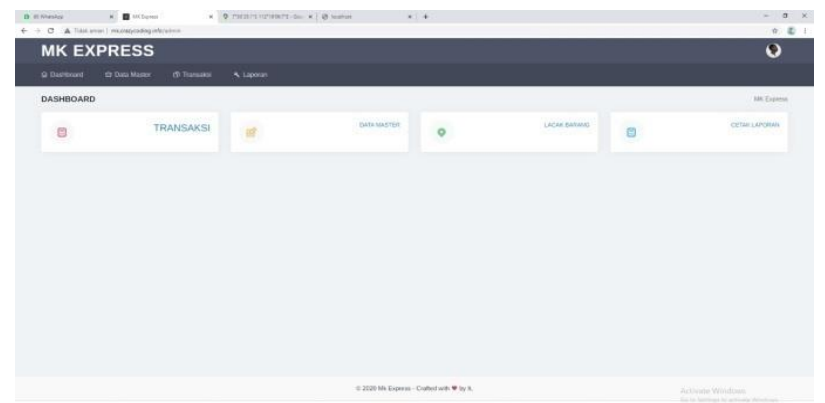

Gambar 14. Halaman Beranda 


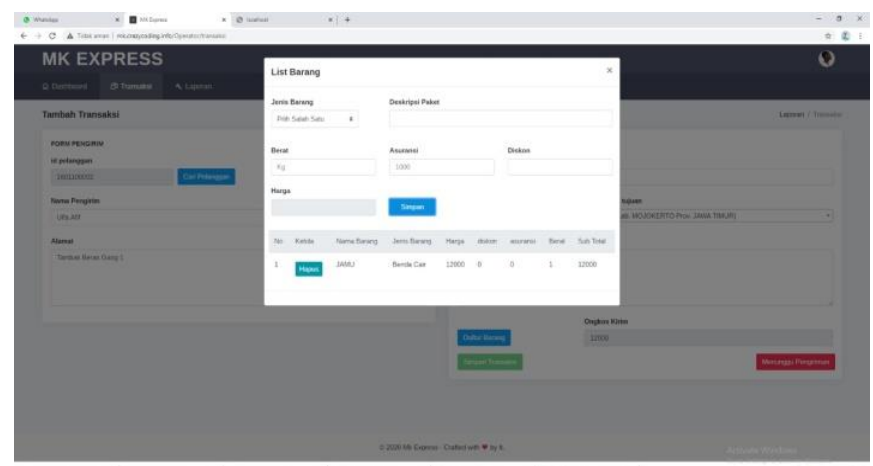

Gambar 15. Halaman Transaksi

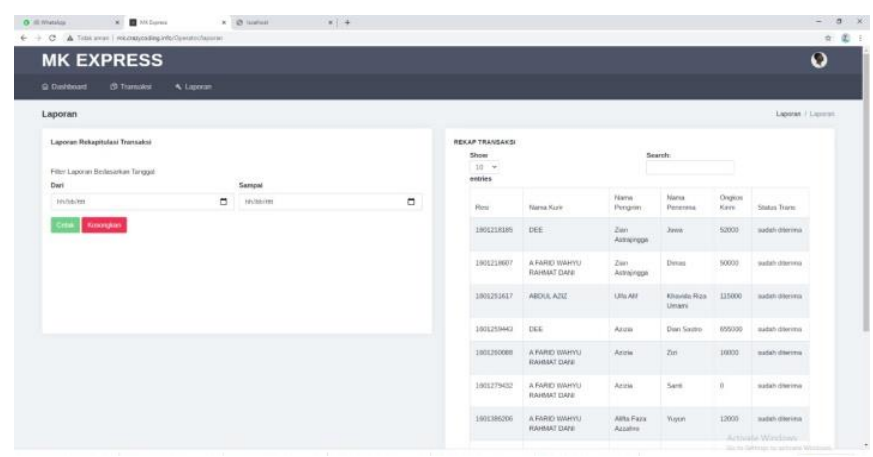

Gambar 16. Halaman Pelaporan

\subsection{Pengujian System}

Pengujian program ini dilakukan dengan menggunakan metode Black Box. Pengujian Black Box adalah pengujian program berdasarkan fungsi dari program. Pengujian metode Black Box ini dilakukan dengan cara memberikan sejumlah input-an pada program yang kemudian diproses sesuai dengan kebutuhan fungsionalnya untuk melihat apakah program menghasilkan keluaran yang diinginkan dan sesuai dengan fungsi program tersebut. Apabila ada input-an yang diberikan proses menghasilkan output-an yang sesuai dengan kebutuhan fungsionalnya, maka program yang bersangkutan telah benar, jika output-an yang dihasilkan tidak sesuai dengan kebutuhan fungsionalnya, maka masih terdapat kesalahan pada program aplikasi. Pengujian ini dilakukan dengan mencoba semua kemungkinan yang memungkinkan terjadi, dan dilakukan berulang-ulang. Jika didalam pengujian ditemukan kesalahan, maka akan dilakukan penelusuran dan perbaikan. Jika perbaikan telah selesai, maka akan dilakukan pengujian kembali. Berikut adalah salah satu pengujian pada proses pelacakan dapat dilihat pada gambar 17 dan gambar 18.

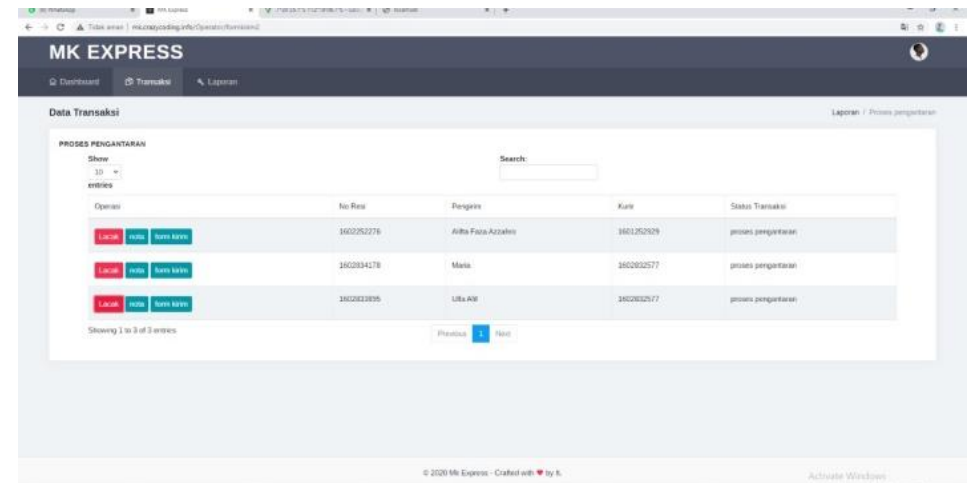

Gambar 17. Halaman Pengujian List Proses Pengantaran (Output Benar) 


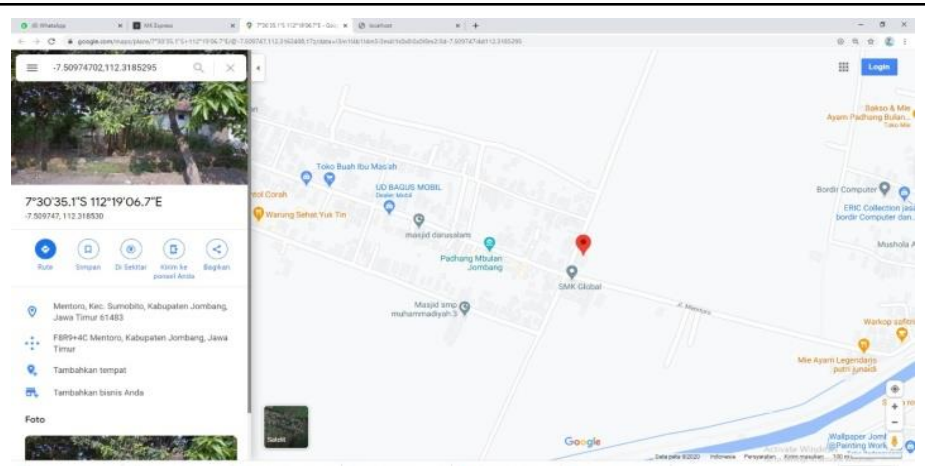

Gambar 18. Halaman Pengujian Lacak pada Proses Pengantaran (Output Benar)

\section{KESIMPULAN}

Kesimpulan berdasarkan implementasi dan pengujian Sistem Informasi Manajemen Pengiriman Paket CV. MK Express, maka dapat disimpulkan bahwa, aplikasi ini dapat memberikan kemudahan kepada perusahaan untuk memanajemen data pelaporan dan pengarsipan perusahaan. Aplikasi ini juga memberikan kemudahan kepada pelanggan untuk mengetahui lokasi yang sedang dikirimkan.Serta memudahkan pelanggan untuk cek harga secara mandiri melalui web front end.

\section{DAFTAR PUSTAKA}

[1] Widiawati, Wina. 2018. "Sistem Informasi Ekspedisi Ekspor Impor Pada PT. Bongsoikrama Lintas Usaha Jakarta". Jurnal Khatulistiwa Informatika, Vol. VI No. 2.

[2] Pramana, Syafii Ade. 2016 . "Kantor Ekspedisi Pengiriman di Kota Pontianak". Jurnal Online Mahasiswa Arsitektur Universitas Tanjungpura, vol. 4 No. 2.

[3] Wicaksono,Teguh Cahyono.Dkk. 2019. "The Influence Of Expedition Couriers, Informations Systems And Consumer Complaints On The Expedition With Service Quality As A Mediating Variable To Increase Customer Satisfaction ( At Pt Jne Express Brach Semarang )". Jurnal Of Management vol 5, no 5 Universitas Pandanaran Semarang.

[4] Awaludin. 2017. "Sistem Informasi Perusahaan Ekspedisi Berbasis Web". JUTISI Vol. 6 STMIK Banjarbaru, No. 3.

[5] Gunawan LN. Dkk. 2018. "Pembuatan Sistem Informasi Administrasi, dan Computer Maintenance Management System pada Perusahaan Ekspedisi X di Surabaya". Jurnal Infra Vol 6, No 1 Universitas Krtisten Petra.

[6] Wicaksono,Teguh Cahyono.Dkk. 2019. "The Influence Of Expedition Couriers, Informations Systems, And Consumer Complaints, On The Expedition With Service Quality As A Mediating Variable To Increase Customer Satisfaction ( At Pt Jne Express Brach Semarang )". Jurnal Of Management vol 5, no 5 Universitas Pandanaran Semarang.

[7] Vendika,Trimanta.Dkk. 2016."Sistem Informasi Manajemen Jasa Ekspedisi Pada CV.Acin Transport Berbasis Web". Jurnal Online STMIK GI MDP, AMIK MDP.

[8] Maulana,Halim. 2016. "Analisis Dan Perancangan Sistem Replikasi Database Mysql Dengan Menggunakan Vmware Pada Sistem Operasi Open Source". Jurnal Nasional Informatika dan teknologi jaringan Vol1,No 1,Universitas Sumatera Utara.

[9] Codeigniter." CodeIgniter Rocks"http://codeigniter.com, [Oct. 19, 2020].

[10] M Fikri Setiadi. "Pengenalan Codeigniter" http://mfikri.com/artikel/Pengenalan-Codeigniter.html, Feb. 02, 2020[Oct. 19,]. 